\title{
Influence of Mobility Management on Hotel Offer
}

\author{
Edna Mrnjavac ${ }^{1,}$ and Nadia Pavia ${ }^{1}$ \\ ${ }^{1}$ University of Rijeka, Faculty of Tourism and Hospitality Management, 51414 Ika, Opatija, Croatia
}

\begin{abstract}
Traffic is one of the biggest pollutants of the environment, which places special challenges before tourism destinations. To protect the environment and, at the same time, to satisfy transport demand, the concept of mobility management has been created, which links tourism, transport and spatial planning in the manner that the existing transport capacities are used in the best possible way. The concept rests on the ecological forms of transport and is realised at the local level by a set of measures - strategies which are directed towards solving of a specific traffic problem and the success of its realisation greatly depends on the cooperation of all stakeholders. This particularly concerns hotels in resorts and towns, which can no longer be reached by car and, bearing in mind tourists' habits, this can represent a serious problem. Ensuring alternatives by which the arrival of tourists at the hotel will be facilitated is one of the attractive elements of offer. Experience based on authenticity and sustainability, with conveniences tourists are used to, is increasingly in demand. The aim of the research is to define the interdependence between the concept of mobility and hotel offer, in the way that the contribution of the chosen mobility strategy of hotel offer competitiveness is specified. The secondary research will be complemented by the primary researches by which the theoretical statements will be specified.
\end{abstract}

\section{Introduction}

Tourism records a continuous increase in flows and new forms of offer. The consequence of a still dominant mass tourism is environmental degradation and devastation, which encourages research and definition of new developmental paradigms which as their goal have to reconcile diametrically different opposing tendencies.

Traffic has no alternatives in accessing destinations or getting around them and, very often, it also takes on the role of a dominant tourism offer motive. Simultaneously, it devastates natural and artificial resources on which tourist activity is based.

The world and European tourism are entirely dependent on air $(55 \%$, i.e. $53 \%)$ and road traffic $(39 \%$, i.e. $36 \%)$, while, in destinations, mobility is reduced to road traffic [1]. The share of other traffic categories is symbolic. In such a traffic framework and in the gap between developmental goals and overall environmental devastation, tourism destinations are, with more or less success, trying to find their sustainable path to the future.

Current trends in transport open some entirely new perspectives. A "new culture for urban mobility" is developed [2], whose aim is to facilitate quality transport in towns and

${ }^{*}$ Corresponding author: ednam@,fthm.hr 
resorts and which will be ecologically sustainable, safe, easily accessible and simple to use. The aim of this goal is also the concept of mobility.

The potential of the mobility concept is great and can solve different transport problems in towns and resorts. A large part of mobility strategies is based on the change of users' attitudes, which would enable the change in the behavioural pattern.

Each destination needs to find its own, optimal, mobility model, which will require changes in the behaviour of tourists, visitors and the local population as well as the intensive strategic cooperation of all stakeholders who will, themselves, have to adapt their own actions and business goals to the common goal

\section{Theoretical Background}

\subsection{Mobility management in tourism}

Tourism destination competitiveness is important, especially for countries which rely on tourism. A destination may be considered competitive if it can attract and satisfy potential tourists [3]. According to Attila [4], destination can only be competitive and successful when there are accommodations, hotels of suitable number and capacity in the area, that can support an increase in guest numbers, their accommodation and stay for a longer time. Aziz and Arifin [5] stress the demand directed towards an authentic tourist offer, acquaintance with the local culture and tradition, experiences based on authenticity and sustainability, but without sacrificing the conveniences they are used to.

According to Manente, Minghetti, and Celotto, E. [6], destinations are mainly faced with similar problems: mobility is based on the use of personal vehicles; consequently, congestion occurs, especially during peak hours, the lack of parking capacities, apart from existing street parking, buses are mainly used for public transport and there is no common IC system for transport and tourism. These transport problems particularly burden historical centres and roads which link tourist accommodation zones (hotels, campsites, private accommodation zones, etc.) with localities which are attractive to tourists [7]. To a certain extent, it is possible to examine tourist mobility patterns and to, in a certain measure, quantify and determine the characteristic movement routes. This is generally not possible for visitor flows.

Mobility management is a concept which links transport, tourism and spatial planning in the manner that it tries to satisfy transport and tourist demand by using the existing transport capacities, primarily the infrastructure, being guided by the principles of environmental protection and traffic safety. The spatial dimension in destinations is very important, as the spatial layout of elements is set by development in previous periods and tourist movement using different routes, which will valorise the space in its entirety, and not only certain locations, is in the interest of the local community [8].

Enoch, M. [9] elaborates the relationship between the terms of mobility management (MM) and transportation demand management (TDM), given that the majority of strategies and measures within the framework of the concept of mobility is directed towards potential users. Marketing and promotion are very important for TDM, as this is the only way to encourage tourists to behave differently in the destination: to not use their personal vehicles, to use other transport models and to park their vehicles according to the principle "park and ride" or "park and walk". As most of the mobility strategies include a "reward" for the choice of a desired behaviour and a "fine" for undesirable behaviour, informing tourists in a timely and detailed manner is of great importance.

The lack of space for construction of the new traffic infrastructure and availability of a certain reserve of capacities besides the existing ones are the motivators of the mobility 
strategies whose aim is to satisfy the demand by means of an efficient use of those capacities which already exist. The results of the research on tourist mobility in the historical town of Burgos in Spain, related to this problem area [10], generated the following measures: coordinate mobility for visitors using cleaner forms of transport; provide incentives for visitors to travel to the city by collective transport (e.g. reduced entrance fees to historical monuments); design tourist routes around cultural and historical sites in the city; promote the use of bicycles, tourist taxis and collective transport among visitors; encourage hoteliers/taxi drivers and information services to participate in the scheme; provide visitor information points and discounts for travel on public transport; support intermodality; and promote the tourist taxi initiative, using vehicles running on cleaner fuels.

Transport demand is derived from tourist demand and thus, by acting on it, we can also directly influence mobility in the destination. The following strategies of tourism demand management are particularly efficient: development of out-of-season offer, development of alternative tourist routes, creation of new attractions and changing of the destination image. The implementation of these strategies especially requires the cooperation and coordinated action of all destination stakeholders - local government, tourism and transport companies [11]. Destinations are directed towards shaping of their own models of mobility management which combine the usual mobility measures and tourism offer specificities.

\subsection{Mobility management and hotel offer - defining research frame and hypothesis}

Hotels and tourist attractions are key actors in any tourism destination. Indeed, they are both places regularly visited by tourists and therefore have a huge potential for the promotion of sustainable transport options among visitors.

Particular attention is drawn to hotels which are situated in the old historical town centres, which enable their guests direct contact with the local population, familiarisation with the local culture and tradition, etc... Shoval, N., McKercher, B., Ng, E., \& Birenboim, A. [12] highlight the importance of hotel location as a critical factor influencing consumption patterns within a destination and it is recognised that tourism is a spatially selective activity and is driven largely by hotel location. In addition to the traditional accommodations arise new forms of hospitality caring about appreciation of the territory and the enhancement of typicality [13].

As a tourism product, hotel product is a specific relationship between services and products which needs to be perceived by the target market as a homogenous unity, whose value and qualitative dimension surpasses the competitive one [14]. Due to the role of vehicles in tourism flows [15], parking of guests' vehicles is an important factor in the hotel offer quality. The location of parking capacities, their distribution in space, the number of parking spaces and the distance from the content of the attraction are the fundamental determinants of provision of quality services of keeping tourist visitors' vehicles and, integrated with other tourist services, also represents a determinant of a quality destination tourism product [16].

The emphasis put on ecological traffic solutions puts before stakeholder's special requirements, which is especially pronounced if the destination applies the "no vehicle" strategy. Hotels in historical town centres are particularly "under attack".

Mobility management has an influence on the overall hotel business, especially on the organisation of business processes. It affects the flows which are important for the hotel function - foodstuff and drink supply, waste disposal and flows of consumables, essential for the hotel business [17]. All of this can be organised within specific time slots, using separate corridors and special, electrically powered, means of transport and of/or of smaller 
capacity. This last option can contribute to the efficiency of hotel operations by a higher frequency of supply and by reduction of supplies and hotel storage capacity. The entire hotel logistics, which is organised in specific conditions, should also encompass the flow of employees and eventual keeping of their transport means.

The second group of flows under the mobility management influence are guest flows (and flows of their vehicles), which can find themselves in the situation where they cannot in any way access the hotel in their vehicles. In the context of the fact that luggage is always also present, guests can be dissatisfied with such a situation. Different options are possible: from time-limited access to the hotel, with parking or without parking, to the impossibility of accessing the hotel in one's own vehicle, which should be solved by the use of a different form of transport, organised by the hotel itself (rental of electric vehicles or bicycles, bus service on request, mobility information centre, bicycle rental, additional transport services, connections between cable cars and railway stations, travel planner, satellite tracking and route planning system, shuttle service, etc.). The growing role of cycling tourism in the overall hotel offer, quotes Slavić, N. [18], calls for hotels to create offers for cyclists according to one or several (possibly all) cyclist segments: mountain cyclist, freeride, road cyclists, leisure cyclists and users of electric bicycles.

The hotel cannot solve on its own all these options of transport accessibility and cooperation is essential with the local government and self-government, destination management, local carriers, besides the already mentioned forms of mobility organised by the hotel itself. Good results are achieved by quality organisation of: pedestrian traffic (for example, coastal promenades), public transport (stations should not be further than approximately 10 minutes away on foot), as well as by different forms of multimodal transport.

Given that the majority of guests use their personal vehicles to travel to the destination, or they hire vehicles, wanting to, at any time, have the feeling of maximal control over their own mobility, hotels should take care of parking capacities and manage them. According to Pupavac D., Maršanić R. [19], parking falls into the category of the service segment which constitutes hotel product at a micro-level, representing a break in the tourist movement process due to a stay in a hotel, i.e. in the destination area.

The tourists' need for keeping their vehicles in the destination is one of the basic determinants of the transport and tourism demand. The research on hotel guest satisfaction shows a lower level of satisfaction if there is not a sufficient number of parking spaces. Parking services are a component of a hotel product and the fact that a hotel provides parking spaces has a direct effect on the satisfaction of guests with the hotel offering as a whole [20].

The aim of this research was to determine in what measure hotels can influence their guests' mobility. In the event of an affirmative attitude, the intention was to ascertain in what ways hotels can contribute to the guests' mobility. Finally, the intention was to establish what the characteristics of the relationship between the mobility management and hotel offer are.

For that purpose, the main hypothesis was defined: Hotels can and need to take an active part in their guests' mobility. Ancillary hypotheses were also defined: hotels can participate in the concept of mobility through cooperation with other stakeholders in the destination. Hotels can directly develop and implement their own mobility measures for their guests. By taking part in the concept of mobility management, hotels influence guest satisfaction by their offer. 


\section{Materials and methods}

There is very little research on mobility management in tourism destinations. The greatest part of the research work relates to specific destinations, implemented concepts of mobility management and obtained results. There is no research on the interrelationship between mobility management and hotel, i.e. hotel offer. Due to the role of both elements in the tourist offer, the intention was to find out whether there are reasons for researching the potential role of hotels within the concept of mobility management.

For that reason, the secondary research relied on the method of analysis, by which the examples of mobility management in tourism and in EU destinations were explored in great detail, which form an integral part of the report on specific projects realised by the European institutions. This facilitated the formulation of conclusions, which were the starting basis for examination of the hotel position in the concept of mobility management, and all that with the aim to, eventually, define universally applicable conclusions.

Due to the fact that old town centres are particularly attractive for tourists, and the same goes for hotel accommodation in those zones, special attention is paid to integrated hotels.

To check the conclusions obtained by the secondary research, the primary research was based on the interview method by means of a survey questionnaire, which consisted of 18 questions. It was sent to the hotel management of the largest integrated hotel in Croatia, more precisely, in Zagreb. The reason for choosing an integrated hotel is that they are always situated in town centres, they consist of three or more accommodation units in different locations with a common reception for guest reception and other activities which affect the quality of guest stays. This type of hotel belongs to new, innovative hotel offer trends and has been dynamically growing in the accommodation capacity market.

The integral hotel specific nature is also the possibility of service provision by external subjects, the local community, which can, within the framework of tourism and hospitality services, put their facilities and services at the disposal of the integrated hotel. The research was conducted during the month of January 2018.

The questions related to the shaping of the offer of hotels located in town historical centres, often inaccessible by vehicles, and an attempt was made to get the answer to the question of how transport accessibility and mobility affects hotel offer competitiveness. The results are synthesised and put in correlation with the research elements in European towns. The obtained results were correlated also with the main mobility determinants, by which a better understanding was enabled of some of the research results, as well as the formulation of recommendations for future research.

\section{Results and discussion}

Location of hotels in town centres usually mean that tourist attractions are not far away but, at the same time, it also means hindered accessibility or even the impossibility of access by motor vehicles. Consequently, the characteristics of integrated hotels point to the strong possibility that they are not able to provide a sufficient number of parking spaces, or that they do not have any at all.

The integrated hotel management emphasises that guests who visit Zagreb are mostly so-called leisure guests, who begin and end their stay in Zagreb and much less business guests. They wish to feel at home, planning their time as they see fit. Integrated hotels, with accommodation units which are spread around the whole of the town central parts do not form a specialised or themed hotel offer nor is specialised promotion made.

Business policy is especially focused on education of employees for quality information provision to guests about different events and attractions in the town. In that context, cooperation with the Town Tourism Board, which, in the course of recent years, has 
supported a large number of events, among other things also through promotional materials which are available in every info centre in the town, as well as through printed materials, which are delivered upon request to hotels and which contain information about current and future events.

The characteristics of Zagreb, as a tourism destination, facilitate all-year hotel operations. Hotel management tries to alleviate oscillations in demand by a thoroughly elaborated commercial policy of stimulating prices in the periods of lower demand and, simultaneously, during the periods of $90 \%$ capacity occupancy, the prices rise. This approach unquestionably reminds us of the low budget air carriers' basic principle.

The integrated hotel offer innovativeness is reflected in the location and characteristics of accommodation units (apartment, rooms or boutique hotels) which provide the freedom of planning of time and activities. The hotel owners and management are focused on maximal quality of accommodation with reasonable prices and on the development of optimal sales channels, given that the largest part of their market is made up of individual tourists.

The location of the integrated hotel in Zagreb opens the question of accessibility, mobility and possibility of parking. Parking is dealt with depending on the location of the accommodation unit. Nearly one half of apartments have provided parking - free parking in a private garage or a designated parking space which is charged for per day of stay in the apartment. The nearest public garage, up to 10 minutes away on foot, is recommended to guests staying in apartments without provided parking spaces or in apartments in the locations which are not accessible by vehicles. This parking service is charged separately.

In information about the hotel offer, special attention is paid to the description of the hotel location, possibility of reaching the apartment (if it is not possible by vehicle) and the parking mode. Confirmation of accommodation booking also contains information about the parking mode. In relation to this, cooperation with the bearers of the town transport policy, companies which manage public garages and public transport is of great importance in the provision of the mobility of hotel guests.

This knowledge is identical to the research results on the role of parking in Croatian destinations, stating that detailed and timely (prior to arrival in the destination) informing of tourists is very important. If that condition is met and guests know in advance how the mobility is organised in the destination, including parking and getting about, they do not think that the limitations of vehicle use represents a shortcoming.

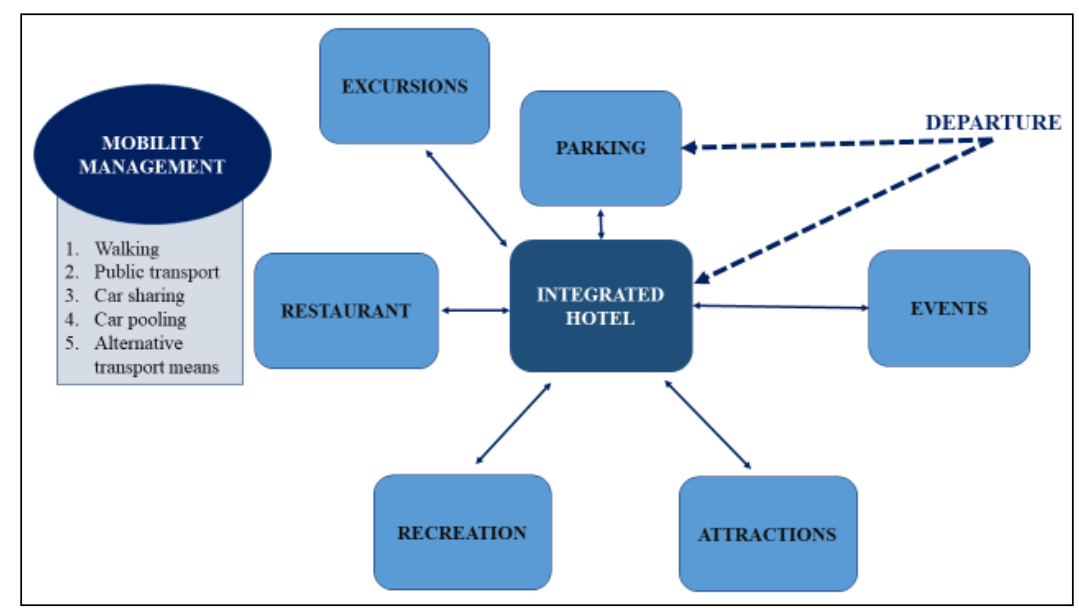

Fig. 1. Interdependence mobility management and hotel offers. 
By the research, it is confirmed that there is a correlation between mobility and the hotel offer quality, because the hotel management pays particular attention to the quality of information about the location of the hotel facility, modes of access to it and the possibilities of parking. Depending on the hotel location and destination characteristics, hotels can and need to directly participate in their guests' mobility. What they do, as they recognise the importance of it for guests, is to inform their guests about parking possibilities. This research, but also some other similar ones, conducted in other Croatian destinations, showed that guests do not think it negative that there are no provided parking spaces for their vehicles on the condition that they are adequately informed about it beforehand. This knowledge is extremely important because it points to the possibility that tourists would be prepared to accept also some other models of mobility (for example, bigger limitations in vehicle use or even a "car-free city") provided they are offered a quality mobility model in the destination and that they are accordingly informed about it in advance.

The research also pointed to the great importance of cooperation with other stakeholders in the destination concerning tourism offer creation and availability of information about it. This certainly includes also most diverse forms of mobility such as: city public transport, tourist buses, tourist trains, cable cars, pedestrian tourist routes, car sharing, public bicycles, Segway rental and numerous other forms of mobility for visitors.

The hypothesis that hotels can develop their own mobility models is partly confirmed, as the researched hotel does not have such an offer organised. Such a possibility would be more suited to large capacity hotels, concentrated in a single place and at a greater distance from the historical town centre and most of the attractions.

The hypothesis that the mobility management concept affects guest satisfaction is confirmed by the research - certainly in the part which relates to a provided parking space. This results from the attention which hotel managers attach to informing their guests about it (and about other forms of mobility in a town), but also from the dissatisfaction which is the consequence of insufficiently precise information about the conditions of accommodation in a hotel.

\section{Conclusion}

Tourism is organised as a dynamical system, composed of numerous commercial and noncommercial activities which shape a tourism product. The competitive tourism market and increasingly demanding tourists force the tourism offer bearers to make structural changes. New tourism demand trends stress the need for new and sophisticated tourist accommodation which creates extraordinary experiences. At the same time, as an expression of a need to link transport, tourism and available space in an optimal manner, a concept of mobility management is being developed, by which the transport and tourism demand tries to be met with the existing transport capacities, primarily with the infrastructure, guided by the principles of environmental protection and traffic safety. The accent is on the new forms of organisation of smart transport chains, with an emphasis on alternative transport forms.

The interdependence between the mobility concept and hotel offer is explored in the paper. The research encompassed an integrated hotel, one of the new innovative hotel facilities, characteristic for its location in the town centre and its dislocation of accommodation capacities. Given that the majority of guests use personal vehicles as their means of access and mobility in the destination, they come across the problem of parking as, due to the hotel location, there is either insufficient number of parking spaces or there are not any. 
It is confirmed by the research that there is correlation between mobility and quality of hotel offer, which is evident from the fact that hotel management pays special attention to the provision of quality information about the location of the accommodation facility, modes of access to it and parking possibilities. Guests do not take the absence of provided parking spaces as a negative thing provided that they had been accordingly informed prior to their arrival. This knowledge is extremely important because it points to the possibility that tourists would be prepared to accept also some other models of mobility (for example, bigger limitations in vehicle use or even a "car-free city"), provided they are offered a quality mobility model in the destination and that they are accordingly informed about it in advance. From the scientific aspect, it would, therefore, be worth researching under which conditions visitors would be prepared to arrive in a destination without their own vehicles.

The great importance of cooperation with the other stakeholders in the destination concerning tourism offer creation and availability of information about it is also confirmed. This certainly also includes most diverse forms of mobility, which are in the domain of stakeholders in tourism destinations. The premise that hotels can develop their own mobility models is only partly correct and is acceptable for large capacity hotels, concentrated in a single location and at a larger distance from the historical centre and most of the attractions.

This paper was written within the framework of the project "Supply Chain Management in Hospitality". This research was financially supported by the University of Rijeka, for the project 13.03.1.2.01.1.

This paper was written within the framework of the project "Innovative accommodation facilities aimed at enhancing the competitiveness of a tourism destination". This research was financially supported by the University of Rijeka, for the project ZP UNIRI 7/16.

\section{References}

1. UNWTO Highlights (2017)

2. Commission of the European Communities, Green paper - Towards a new culture for urban mobility, pp. 6-17 2007

3. H. Tsai, H. Song, K.K.F. Wong, Tourism and Hotel Competitiveness Research, Journal of Travel \& Tourism Marketing, 26, 5-6 (2009)

4. A.T. Attila, The Impact of the Hotel Industry on the Competitiveness of Tourism Destination in Hungary, Journal of Competitiveness, 8, 4 (2016)

5. N.A. Aziz, A.A. Ariffin, Identifying the Relationship between Travel Motivation and Lifestyles among Malaysian Pleasure Tourists and Its Marketing Implications, International Journal of Marketing Studies, 1, 2 (2009)

6. M. Manente, V. Minghetti, E. Celotto, Visitor and mobility management in tourism destinations: A cross analysis of strategies, projects and practices, Tourism Review, 55, 2 (2000)

7. M. Engelskirchen, Sustainable Transport: A Sourcebook for Policy-makers in Developing Cities (2002)

8. D.I. Edwards, T. Griffin: Understanding tourists 'spatial behaviour: GPS tracking as an aid to sustainable destination management, Journal of Sustainable Tourism, Routledge, 21, 4 (2013)

9. M. Enoch. Ashgate Publishing Limited, Farnham, Surrey (2012)

10. CIVITAS 2020. http://civitas.eu/measure/new-mobility-services-tourists)

11. Sustainable transport: A Sourcebook for Policy-makers in Developing Cities, Module 2b: Mobility Management, GTZ (2003) 
12. N. Shoval, B. McKercher, E. Ng, A. Birenboim, Hotel Location and Tourist Activity in Cities, Annals of Tourism Research, 38, 4 (2011)

13. C. Vallone, V. Veglio, „Albergo Diffuso“ and Customer Satisfaction: A Quality Services Analysis”. Proceedings, 16th Toulon-Verona Conference ,Excellence in Services“, University of Ljubljana, Slovenia, 29-30 August 2013 (2013)

14. E. Mrnjavac, R. Maršanić, Parkiranje - Element kvalitete hotelskog proizvoda, In E. Mrnjavac (Eds.), Supply Chain Management in Hospitality Industry, Fakultet za menadžment u turizmu i ugostiteljstvu Opatija (2018)

15. S. Čorak, Z. Marušić, et. al., Stavovi i potrošnja turista u Hrvatskoj - TOMAS ljeto 2014. Institut za turizam. Zagreb (2015)

16. D. Pupavac, R. Maršanić, Lj. Krpan, Significance of stationary traffic as factor in logistics systems in tourist destinations. In I. Vrdoljak Raguž and I. Lončar (Eds.), DIEM 2013. Dubrovnik (2013)

17. E. Mrnjavac, N. Pavia, M. Cerović, Procurement in the Supply Chain: An Element of Hotel Product Competitiveness, Contemporary Economy, 7, 2 (2016)

18. N. Slavić, Hotelski logistički proizvod u ponudi sportskog turizma, doktorska disertacija, Fakultet za menadžment u turizmu i ugostiteljstvu, Opatija (2014)

19. D. Pupavac, R. Maršanić, Parking policy - development factor for the tourist destinations. In J. Perić (Eds.), Proceedings $21^{\text {th }}$ Biennial International Congress Tourism \& Hospitality Industry 2012. New Trends in Tourism and Hospitality Management. Opatija (2012)

20. R. Maršanić, E. Mrnjavac, Role of parking in the hotel supply chain management, LogForum, Scientific Journal of Logistics, 11, 4 (2015) 